\title{
Therapy of autoimmune bullous diseases
}

\author{
Diya F Mutasim \\ Department of Dermatology, \\ University of Cincinnati College of \\ Medicine, Cincinnati, OH, USA
}

\begin{abstract}
Autoimmune bullous diseases result from an immune response to molecular components of the desmosome or basement membrane. Bullous diseases are associated with a high degree of morbidity and occasional mortality. Therapy of bullous diseases consists of suppressing the immune system, controlling inflammation and improving healing of erosions. The therapeutic agents used in the treatment of bullous diseases may be associated with high morbidity and occasional mortality. Successful treatment requires understanding of the pathophysiology of the disease process and the pharmacology of the drugs being used.

Keywords: autoimmune, bullous, therapy
\end{abstract}

\section{Introduction}

The autoimmune bullous diseases are a group of skin disorders that result from autoimmunity against intercellular adhesion molecules or components of the basement membrane in the skin and mucosal surfaces. Desmosomal proteins have important function in intercellular adhesion. Autoimmunity to desmosomal proteins results in various forms of pemphigus (Beutner and Jordon 1964; Anhalt et al 1982; Roscoe et al 1985; Eyre and Stanley 1988; Amagai et al 1991; Rappersberger et al 1992; Karpati et al 1993; Stanley 1993). Evidence from in vitro studies as well as animal models of pemphigus in mice supports the hypothesis that pemphigus antibodies result in loss of cellular adhesion and, hence, blister formation by directly interfering with desmosomal function (Amagai et al 1992, 1994, 2000). The bullous diseases that result from autoimmunity to components of the basement membrane (Stanley 1989; Diaz and Giudice 2000) are secondary to activation of the complement system that leads to an influx of inflammatory cells (Liu et al 1993, 1997). The specific molecules that are the target of the autoimmune response in bullous diseases are shown in Table 1. The diagnosis of autoimmune bullous diseases is based on clinical, histologic and immunofluorescence findings. Histologic examination of an early intact vesicle usually reveals the characteristic findings. Direct immunofluorescence is performed on normal skin adjacent to a lesion. Indirect immunofluorescence is performed on the patient's serum (Mutasim and Adams 2001).

The discussion about pharmacologic agents in this article is for off-label use. The drugs have not been approved for the treatment of autoimmune bullous diseases and they have not been evaluated by double-blind placebo-controlled studies. There are multiple reasons for the lack of controlled studies. They include the rarity of autoimmune bullous disorders, the potentially serious morbidity associated with most cases and the ethical dilemma of withholding treatment (placebo) to a patient with a serious disorder. The quality of evidence-based practice guidelines is therefore variable. Most data are derived from case reports and case series. Critical interpretation of the literature as well as reporting the personal experience of the author with a large number of patients will be presented (Mutasim 2004).

\section{Therapy of pemphigus vulgaris}

Pemphigus vulgaris (PV) autoantibodies are directed against desmoglein III (DG III), a component of the desmosomes that are essential for intercellular adhesion in 
Table I Molecular classification of bullous diseases

\begin{tabular}{ll}
\hline Bullous disease & Targeted molecule/organelle \\
\hline Pemphigus vulgaris & Desmoglein III \\
Pemphigus foliaceous & Desmoglein I \\
Paraneoplastic pemphigus & Desmoplakin I, Desmoplakin II, \\
& BP 230, Envoplakin, Periplakin, \\
& Desmoglein III, Plectin, Other \\
IgA Pemphigus & Desmocollin I \\
Bullous pemphigoid & BP I80, BP 230 \\
Mucous membrane pemphigoid & BP I80, laminin 5 \\
Epidermolysis bullosa acquisita & TypeVII collagen \\
Dermatitis herpetiformis & Unknown \\
\hline
\end{tabular}

Abbreviations: $\mathrm{BP}$, bullous pemphigoid ; IgA, immunoglobin A.

skin and stratified squamous epithelium. Experimental evidence confirms the hypothesis that PV antibodies induce lesions by directly disrupting the function of desmosomes. For example, passive transfer of immunoglobin $\mathrm{G}$ (IgG) from $\mathrm{PV}$ patients induces blister formation in neonatal mice (Anhalt et al 1982). Passive transfer of immunoglobulin fractions that have been immunoabsorbed with pemphigus antigen do not cause blister formation (Amagai et al 1994). Inactivation of DG III in a knock-out mouse model results in lesions similar to those in patients with PV (Koch et al 1997). The above evidence indicates that antibodies to DG III result in incomplete assembly or disruption of desmosomes, followed by loss of intercellular adhesion and blister formation. The role of therapy in patients with PV is to suppress the immune system and prevent the production of the pathogenic antibodies. This would result in healing of existing lesions and prevention of the appearance of new lesions. Immunologic remission is indicated by a significant decrease or absence of pathogenic antibodies in the serum and skin of patients with PV. There has been a significant decrease in the mortality of patients with PV since the availability of glucocorticoids and, later, non-steroidal immunosuppressive drugs. Prior to the availability of these drugs, the mortality rate due to the disease was $50 \%$. Presently the mortality rate is less than $10 \%$ and is primarily due to complications of therapy.

The choice of therapy depends only to a slight degree on the severity of the disease at presentation. The usual course of $\mathrm{PV}$ is unrelenting and progressive. Hence, patients who present with limited disease may still be treated "aggressively". Unless there is an absolute contraindication, the initial drug is a systemic glucocorticoid. Topical and intralesional glucocorticoids have also been used in the treatment of mild PV (Bystryn and Steinman 1996; Dumas et al 1999), however, they are rarely effective.
Both prednisone and methylprednisolone may be used. The starting dose of prednisone is $1 \mathrm{mg} / \mathrm{kg} /$ day divided into two or three doses. An equivalent dose of methylprednisolone may be substituted. Depending on the severity of the disease and its duration, patients obtain a clinical remission within $4-12$ weeks. This is usually accompanied by a decrease in the amount, or absence, of circulating PV antibodies in the patient's serum. The dose is maintained for $6-10$ weeks in order to further suppress the immune response. If the patient remains in clinical remission, the dose is then decreased by $10-20 \mathrm{mg}$ every 2-4 weeks. When the dose is $40 \mathrm{mg}$ daily, dosing may be changed to every other day. This transition may be accomplished by doubling the dose to $80 \mathrm{mg}$ daily, followed by a day with no treatment ( $80 \mathrm{mg}$ on alternate days). The dose is then gradually decreased. Alternatively, the transition may be accomplished (author's preference) by keeping the first day dose at $40 \mathrm{mg}$ and decreasing the next day's dose by $5-10 \mathrm{mg}$ every $2-4$ weeks. When the dose is $40 \mathrm{mg}$ every other day, it may be tapered by $5 \mathrm{mg}$ every $2-3$ weeks. If there is no recurrence, the patient is maintained on $5 \mathrm{mg}$ daily for several years in order to avoid recurrences.

In patients who have severe disease or who are not responding adequately to the standard dose of prednisone, the dose may be increased to 1.5 or $2 \mathrm{mg} / \mathrm{kg}$ /day until remission. Alternatively, intravenous methylprednisolone $1 \mathrm{~g}$ daily may be given for three consecutive days. This procedure is referred to as pulse-steroid therapy. Its goal is to achieve a rapid immunosuppressive effect of the glucocorticoid while avoiding the long term side effects (Werth 1996).

"Adjuvant immunosuppressive therapy" refers to the addition of a non-steroidal immunosuppressive agent to the glucocorticoid. Adjuvant therapy may be used in two ways. First, it may be used in patients who fail to obtain a remission or who experience serious adverse effects secondary to glucocorticoid therapy. Second, it may be used concomitantly with glucocorticoid therapy to decrease the total dose of glucocorticoid needed and, hence, the adverse effects. The concomitant use of adjuvant therapy allows the glucocorticoid dose to be tapered rapidly. Patients are maintained on the "steroid-sparing" agent for 18-24 months. The most commonly used steroid-sparing immunosuppressive agents are azathioprine, mycophenolate mofetil (MMF), and cyclophosphamide.

Azathioprine is likely the most commonly used steroidsparing agent world wide. In a review (Bystryn and Steinman 1996) of seven studies involving 105 patients, remissions 
were induced in $28 \%$ of patients. Azathioprine is usually well tolerated. It is a purine analog. The usual dose is $3-$ $4 \mathrm{mg} / \mathrm{kg} /$ day that may be taken once daily or in divided doses. Azathioprine is metabolized through multiple pathways. One pathway involves an enzyme (thiopurine methyltransferase [TPMT]) whose level varies among individuals. It is deficient in approximately 1 in 300 Caucasian individuals. The dose of azathioprine is usually adjusted to the level of TPMT. Individuals with absent TPMT should not receive azathioprine. Individuals with high levels of TPMT may require relatively high doses of the drug. Azathioprine is well tolerated. It may result in gastrointestinal intolerance, mild hepatotoxicity, and bone marrow suppression (commonly of the leukocyte series). Azathioprine should not be given to women who are considering becoming pregnant.

MMF is a relatively safe steroid-sparing agent that was first used for PV in 1997 (Enk and Knop 1997). Its use was later reported (Enk and Knop 1999) in 12 patients who failed combination therapy with prednisone and azathioprine. The dose of MMF used was $1 \mathrm{~g}$ twice daily. Eleven of the 12 patients had improvement without relapse during a 9-12 month follow-up period. MMF has recently been reported to be effective as monotherapy (Bredlich et al 1999; Grundmann-Kollman et al 1999). Other reports have confirmed the efficacy of MMF as adjuvant therapy in the treatment of PV (Mimouni et al 2003). MMF is a purine analog antimetabolite whose kinetics and metabolism show great intra-individual and inter-individual variability. It is usually well tolerated. Adverse effects include occasional gastrointestinal upset and mild dose-related bone marrow suppression.

Cyclophosphamide is an alkylating cytotoxic agent that is a highly effective steroid sparing agent. In a review (Bystryn and Steinman 1996) of five studies with a total of 51 patients, complete remission was achieved in $32 \%$ of patients. The rate of remission for each of the five studies that were reviewed was very wide $(0 \%-80 \%)$, reflecting the small number of patients in each study. Cyclophosphamide has been used as pulse therapy ( $1 \mathrm{~g}$ intravenously every four weeks) (Fellner and Sapadin 2001). This therapy produces much less adverse effects and may be equally effective in some patients. Immunoablative high dose cyclophosphamide $(50 \mathrm{mg} / \mathrm{kg}$ intravenously daily for four consecutive days) without stem cell rescue has been advocated and reported to be effective in resistant cases (Hayag et al 2000; Nousari et al 2003). Cyclophosphamide alkylates DNA at various sites, resulting in cell cycle arrest,
DNA repair and cell death. Proliferating tissues are most susceptible to its effect. The toxicity of cyclophosphamide is significantly higher than that of azathioprine and MMF. Acute myelosuppression is common (nadir at 6-10 days and recovery in 14-21 days). Other adverse effects include mucosal ulcers, alopecia, nephrotoxicity, urotoxicity (hemorrhagic cystitis), cardiotoxicity, hepatotoxicity, interstitial lung fibrosis, and toxicity in reproductive systems resulting in amenorrhea that may be permanent, and azoospermia that may be reversible. Cyclophosphamide is mutagenic and carcinogenic and its long term use has been associated with acute non-lymphocytic leukemia.

Methotrexate is a generally less effective steroid-sparing agent in the treatment of PV. Nine patients (Smith and Bystryn 1999) with steroid-dependent PV underwent the addition of oral methotrexate (starting at $7.5 \mathrm{mg}$ weekly and increasing by $2.5-5 \mathrm{mg}$ every two weeks as needed). Six of the nine patients underwent significant improvement that allowed the glucocorticoid to be discontinued. Upon discontinuing methotrexate, however, the disease flared (mean duration 23 days). In the author's judgment, methotrexate use may be attempted only if there are contraindications to the use of other more effective steroidsparing agents. Methotrexate is an antimetabolite and a folic acid analog. Its toxicity may affect multiple organs including the bone marrow (suppression), gastrointestinal epithelium (ulcers), hair follicles (alopecia), kidneys (nephrotoxicity), lungs (interstitial pneumonitis), liver (hepatitis and cirrhosis), and reproductive organs (defective spermatogenesis and oogenesis).

The response of PV to cyclosporine is not clearly understood and is not as predictable as that to azathioprine, MMF or cyclophosphamide (Thivolet et al 1985; Barthelemey et al 1988; Alijotas et al 1990; Lapidoth et al 1994; Mobini et al 1997; Ioannides et al 2000). In a report (Thivolet et al 1985) of two patients who were not responsive to prednisone $1 \mathrm{mg} / \mathrm{kg} / \mathrm{day}$, the addition of cyclosporine $6 \mathrm{mg} / \mathrm{kg} /$ day resulted in improvement 10-15 days after initiation of therapy. Another report (Alijotas et al 1990) confirmed a response of severe PV in two siblings to cyclosporine monotherapy. The addition of cyclosporine (initial dose $5 \mathrm{mg} / \mathrm{kg}$ day, adjusted to achieve blood levels of $100-150 \mathrm{ng} / \mathrm{ml}$ ) in 16 patients who were also taking prednisone $60-80 \mathrm{mg}$ daily resulted in a reduction of the time to new blister formation, the mean total dose of prednisone needed, and the duration of hospital stay (Lapidoth et al 1994). The control group consisted of 15 patients who were treated with high dose prednisone 
(120 mg daily). Cyclosporine (1-3 mg/kg day adjusted to obtain a serum level of $100-125 \mathrm{ng} / \mathrm{ml}$ ) was highly effective in a group of six patients with severe PV who were unresponsive to multiple previous therapies including glucocorticoids, azathioprine, cyclophosphamide, dapsone, gold and methotrexate (Mobini et al 1997). Near complete clinical remission was obtained by 20 weeks. No recurrences occurred during a 3.5-5 year follow-up period during which no systemic treatment was given. Finally, the addition of cyclosporine to glucocorticoid was shown to be ineffective in a group of 33 patients hospitalized with PV (Ioannides et al 2000). In conclusion, cyclosporine may be effective for selected patients. Its use may be attempted in patients who have failed other immunosuppressive therapies. Cyclosporine potently suppresses cellular immunity and preferentially inhibits antigen-triggered signal transduction in T lymphocytes. This results in decreased expression of several lymphokines, especially interleukin-2. The drug is excreted through bile as metabolites. The dose of cyclosporine needs adjustment in patients with liver failure but not in patients with renal failure. Cyclosporine may be associated with elevation of blood pressure, blood creatinine level, short term as well as long term renal dysfunction, hirsutism, gingival hyperplasia, hyperlipidemia, and neurologic side effects including tremors.

High dose intravenous immunoglobulin (IVIg) has been reported to be of benefit as a steroid-sparing agent in the management of patients with PV. In a review of eight reports (Engineer et al 2000), high dose IVIg was effective in 17 of 18 patients. High dose IVIg should be used as adjuvant to conventional therapy, that is, as a steroid-sparing agent (Colonna et al 1998). In a recent report, 21 patients with severe PV who were unresponsive to treatment with prednisone and multiple immunosuppressive drugs were treated with high dose IVIg (Ahmed 2001). Each cycle consisted of the infusion of a total of $2 \mathrm{~g} / \mathrm{kg}$ body weight over four or five days. All patients obtained clinical remission after a mean duration of 4.46 months. All patients remained in remission after a mean duration of maintenance therapy of 22.7 months and after a mean follow-up period of 20 months following discontinuation of therapy. In another recent report (Bystryn et al 2002), six patients with PV who were unresponsive to conventional therapy were treated with high dose IVIg concurrently with cyclophosphamide. Significant and rapid improvement of their disease was observed. High dose IVIg is a purified human source of $\operatorname{IgG}$ from pooled plasma (Mackay and Rosen 2001). The agent was originally used in small doses for the treatment of congenital immune deficiencies. It is given in a high dose $(2 \mathrm{~g} / \mathrm{kg} /$ cycle $)$ for autoimmune diseases. It is administered as slow infusion up to eight hours. If there is history of previous allergic reaction, the patient is premedicated with steroids or antihistamine. Treatment is repeated every 3-4 weeks until remission occurs. The mechanism of action is unknown. Adverse effects are rare and include fever, headache, myalgia, nausea, tachycardia, dermatitis (Mutasim and Sheth 2002), renal failure, and stroke.

Plasmapheresis consists of withdrawing the patient's blood, using a filter to separate the cellular elements, and returning them to the patient. This procedure results in the removal of the pathogenic antibodies. Its use is usually limited to patients with severe autoimmune disorders. The effectiveness of plasmapheresis, however, is controversial. One study (Guillaume et al 1988) did not find the addition of plasmapheresis to prednisone to be superior to prednisone alone. In another study (Tan-Lim and Bystryn 1990), the addition of plasmapheresis to prednisone (with cyclophosphamide or azathioprine) resulted in a marked decrease in the level of circulating antibodies and decreased disease activity. In order to avoid the rebound phenomenon (patients producing more pathogenic antibodies immediately following plasmapheresis), concomitant use of immunosuppression, preferably with cyclophosphamide, is indicated (Turner et al 2000; Fellner and Sapadin 2001). In conclusion, plasmapheresis in combination with cyclophosphamide may be a valuable treatment for patients with severe disease who are unresponsive to conventional therapy.

Gold is available in parenteral and oral forms. The parenteral forms are completely absorbed, have a half-life of six days and are $70 \%$ excreted in the urine. The oral form is $25 \%$ absorbed with a half-life of 21 days and is excreted through the hepatobiliary tract. The commonly used dose is $10 \mathrm{mg}$ intramuscularly initially, then a $25 \mathrm{mg}$ injection one week later. If there are no adverse effects (see later), $50 \mathrm{mg}$ weekly injections are given subsequently. Oral gold is started at $3 \mathrm{mg}$ twice daily, up to $9 \mathrm{mg}$ daily. When remission is obtained, the dose is decreased and maintained at the lowest dose that keeps the patient in remission. The onset of action is slow with the beneficial effect usually requiring six months of therapy to be appreciated. Gold is usually given concomitantly with glucocorticoids followed by tapering and discontinuation of the glucocorticoid. Patients who undergo remission are maintained on gold (Salomon and Saurat 1986). In a series of 13 patients (Poulin et al 1984) 
who were treated with prednisone and gold, seven had complete remission that required no further treatment. Two patients had recurrences three and five months after discontinuing gold therapy. In another report (Pandya and Dyke 1998), 85\% of 26 patients with pemphigus (21 of whom had PV) responded to therapy. Only four (15\%), however, attained complete remission. In seven patients, prednisone was discontinued and the patients continued to be in remission while on gold therapy alone. Complications of therapy developed in $42 \%$ of patients. The efficacy of gold is generally inferior to that of immunosuppressive drugs. It may be especially useful as maintenance therapy, as well as in patients in their reproductive years because it lacks the carcinogenic and gonadal effects of most other immunosuppressive drugs. The mechanism of action of gold is unknown.

Dapsone has been used by some as an adjunct in therapy of patients with mild PV. There is greater support for its efficacy in another form of pemphigus (pemphigus foliaceus $[\mathrm{PF}]$ ). Of six patients with pemphigus (both $\mathrm{PV}$ and $\mathrm{PF}$ ) treated with dapsone 100-300 mg daily in combination with prednisone, three (type unspecified) had improvement (Bystryn 1984). Further support for the possible role of dapsone is based on a report (Jablonska and Chorzelski 1981) that described a few patients with PV who underwent full remission after the addition of dapsone $100 \mathrm{mg}$ to their previous therapy of glucocorticoid and methotrexate. The small number of cases reported in both series prevents making definitive conclusions about the role of dapsone in the treatment of PV. Dapsone is the prototypic example of the sulfone group of drugs whose mechanism of action is unclear. It inhibits neutrophil chemotaxis. It causes a dosedependent hemolysis that occurs in $100 \%$ of patients who receive a dose equal to or more than $200 \mathrm{mg}$ daily. Patients who are deficient in the enzyme glucose-6-phosphate dehydrogenase are more prone for hemolysis. Methemoglobulinemia is common and may be severe in patients deficient in Met-hemoglobin reductase. Agranulocytosis is a rare, idiosyncratic reaction that occurs within the first three months of therapy. Agranulocytosis is a serious adverse effect that occurs in approximately 1 in 300 individuals. Other adverse effects of dapsone include anorexia, headache, nervousness, peripheral neuropathy, hematuria, hepatitis and multiple skin eruptions.

Extracorporeal photochemotherapy (ECP) is a form of immunotherapy that was first approved for the treatment of cutaneous $\mathrm{T}$ cell lymphomas. The patient ingests a photoactivating agent (methoxypsoralen) 1.5 hours prior to the procedure. Peripheral blood is collected within the ECP unit. A small portion of the peripheral lymphocyte pool is isolated and exposed to ultraviolet A light. Treated lymphocytes along with other cellular and plasma components are reinfused into the patient. The procedure lasts approximately three hours and is repeated the next day. The patient is given a cycle every four weeks. The precise mechanism of action of ECP is unknown. ECP is reserved for patients with PV who fail drug therapy. In 1990, four patients were reported who received glucocorticoid and immunosuppressive therapy along with ECP (Rook et al 1990). All patients showed response to treatment. Another report describes three patients who failed immunosuppressive agent therapy, but who showed complete remission following ECP (Wollina et al 1999). Because of the limited availability of ECP, its high cost, and the lack of controlled trials, ECP is limited for patients who have failed glucocorticoid and other immunosuppressive therapies.

Rituximab is a chimeric monoclonal antibody against CD20 on the surface of mature B cells and plasma cells. Rituximab has been effectively used in the treatment of $B$ cell lymphomas. Its use has been reported to be beneficial in individual cases of resistant PV (Salopek et al 2002; Dupuy et al 2004; Espana et al 2004). The dose is $375 \mathrm{mg} /$ $\mathrm{m}^{2}$ intravenously every week. Figure 1 is an algorithmic approach to the treatment of patients with PV.

\section{Management of pemphigus foliaceus}

PF is associated with lower morbidity than PV. Patients do not have mucosal lesions (which are invariable in patients with PV). The principals and practice of treating patients with PF are similar to those for PV. The reader is referred to specific literature for the management of patients with $\mathrm{PF}$ (Bystryn 1984; Basset et al 1987; Hymes and Jordon 1992; Leibowitz and Voss 1993; Bystryn and Steinman 1996).

\section{Therapy of paraneoplastic pemphigus}

Paraneoplastic pemphigus (PNP) is a multiorgan disorder in which patients develop a unique mucocutaneous eruption in association with an underlying neoplasm, most commonly of B cell lineage (chronic lymphocytic leukemia, nonHodgkin's B cell lymphoma, thymoma and Castleman disease). In general, successful treatment of the underlying condition results in marked improvement or resolution of the mucocutaneous bullous and erosive disorder. Skin lesions tend to respond more rapidly than mucosal lesions. 
The first line agent is usually systemic glucocorticoid (1$2 \mathrm{mg} / \mathrm{kg} /$ day). Patients tend to have a partial response (Anhalt 1997; Dega et al 1998).

One patient with chronic lymphocytic leukemia (Perniciaro et al 1994) was treated with cyclosporine $5 \mathrm{mg}$ / $\mathrm{kg}$ daily in combination with prednisone $35 \mathrm{mg}$ daily. The combination therapy resulted in marked improvement within two months. The combination of intravenous dexamethasone and cyclophosphamide was reported to be effective in one patient. One patient with PNP and chronic lymphocytic leukemia had marked improvement with high dose cyclophosphamide therapy without stem cell rescue (Nousari, Brodsky, et al 1999). Rituximab was effective in a patient with PNP associated with CD20+ follicular lymphoma (Borradori et al 2001) and a case of PNP associated with follicular non-Hodgkin's lymphoma (Heizmann et al 2001). The dose is $375 \mathrm{mg} / \mathrm{m}^{2}$ intravenously every week. Significant improvement has been reported with plasmapheresis (Fullerton et al 1992; Su et al 1994; Izaki et al 1996). Finally, a patient who failed glucocorticoid therapy and excision of an associated inflammatory myelofibroblastic tumor of the upper mediastinum had significant improvement following immunoapheresis. Immunoapheresis is a procedure in which the pathogenic antibodies are adsorbed by sheep anti-human IgG beadformed agarose gel. The patient underwent two or three sessions per week for four weeks (Schoen et al 1998).

\section{Therapy of bullous pemphigoid}

Bullous pemphigoid (BP) results from an autoimmune response and is mediated by a prominent cellular inflammatory infiltrate rich in eosinophils. Unlike PV, BP may remit spontaneously. Unlike therapy for PV, effective treatment of BP may be accomplished with lower doses of immunosuppressive drugs and/or anti-inflammatory agents. Potent topical steroids should be considered and favored in the management of localized or limited disease. In a recent report, potent topical steroid therapy was equivalent to oral glucocorticoid therapy for both moderate and severe BP (Joly et al 2002). In the study, with a total of 341 patients, the end point was overall survival at one year. In patients with extensive BP, topical glucocorticoids resulted in a $43 \%$ reduction in the one year mortality compared with the prednisone $1 \mathrm{mg} / \mathrm{kg}$ /day group. This study may be criticized as to its choice of the end point. The end point most practitioners use is resolution of clinical disease and maintaining remission with the least possible dose of drug therapy.

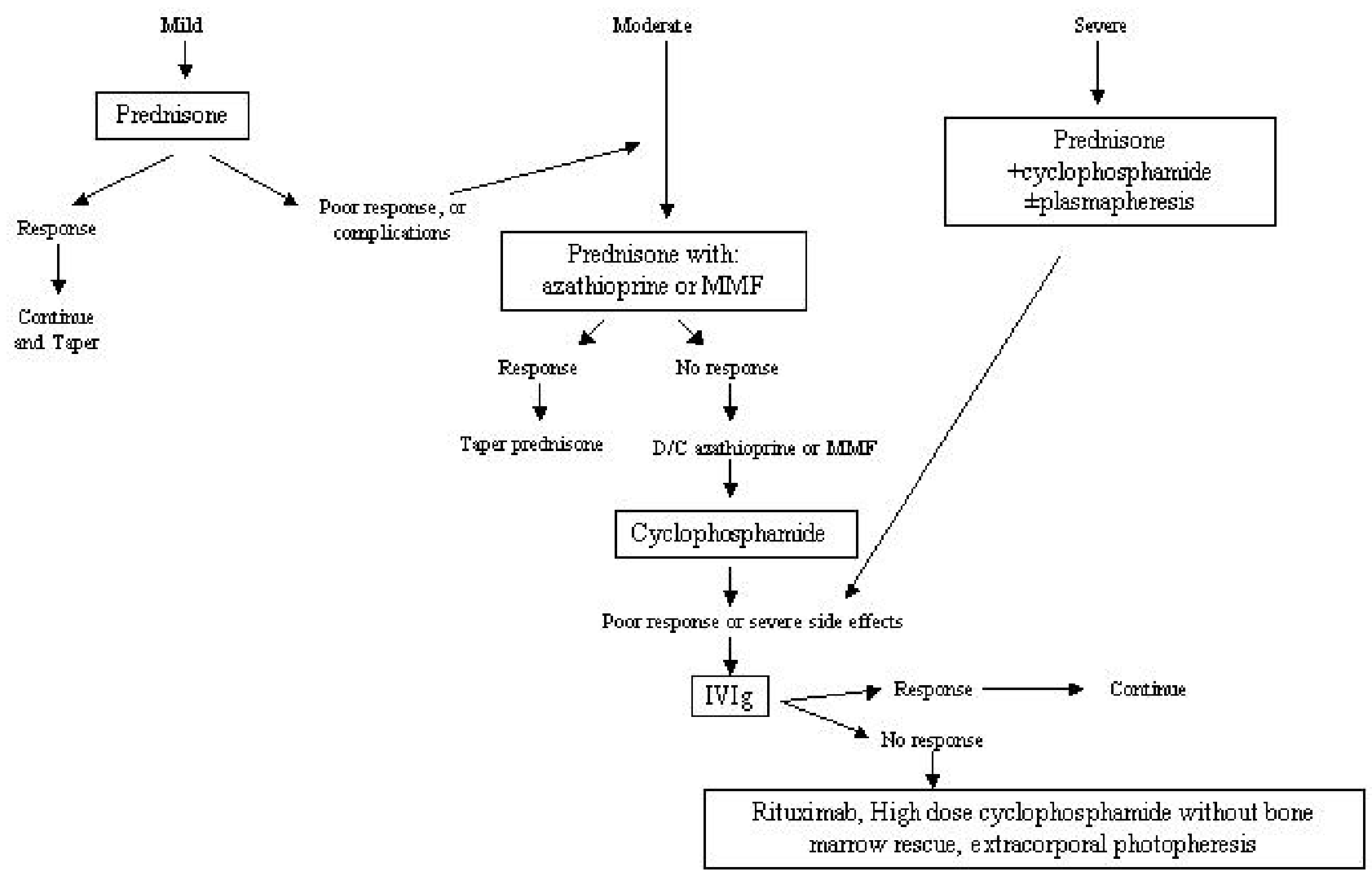

Figure I Algorithmic approach to the treatment of pemphigus vulgaris.

Abbreviations: IVlg, intravenous immunoglobulin; MMF, mycophenolate mofetil. 
Most patients with generalized BP require systemic therapy, the most commonly used agents being glucocorticoids (Church 1960; Siegel and Eaglstein 1984). Systemic glucocorticoids are usually sufficient as the sole therapy in the majority of cases. The dose is $0.5-0.75 \mathrm{mg}$ / $\mathrm{kg} /$ day. Unlike patients with PV, higher doses of prednisone are rarely needed. A clinical response is usually attained rapidly (within 1-3 weeks) and is heralded by healing of existing lesions and cessation of new blister formation. The prednisone dose is then gradually tapered to $5 \mathrm{mg}$ daily over a period of 5-6 months. The guidelines for the tapering procedure are similar to those used for PV. In patients who have high morbidity secondary to extensive skin disease, steroid pulse therapy with methylprednisolone $1 \mathrm{~g}$ daily for three consecutive days may be used for the initial rapid control of the disease. Immunosuppressive drugs are rarely needed in patients with BP. They may be used in patients who require high maintenance doses of glucocorticoids, for patients who are experiencing adverse effects from glucocorticoids, and for those whose disease does not respond completely to glucocorticoid therapy. The most commonly used agents are azathioprine (Greaves et al 1971; Burton and Greaves 1974), MMF (Nousari et al 1998; Wojnarowska et al 2002), and methotrexate (Downham and Chapel 1978). Cyclophosphamide is rarely indicated (Krain et al 1972). MMF is effective both as a sole agent as well as in combination with glucocorticoids (Nousari et al 1998; Grundmann-Kollman et al 1999; Nousari, Brodsky, et al 1999; Nousari, Sragovich, et al 1999). The dose is usually $1 \mathrm{~g}$ twice daily. The dose of azathioprine is $1-3 \mathrm{mg} / \mathrm{kg}$ daily. The dose may be adjusted based on the clinical response, side effects and the level of TPMT. Methotrexate is effective in relatively small doses (up to $12.5 \mathrm{mg}$ weekly) as a sole therapy (Heilborn et al 1999). Chlorambucil $2 \mathrm{mg}$ daily has been reported to result in a reduction in the amount of glucocorticoids required for the control of $\mathrm{BP}$ in 23 patients (Milligan and Hutchinson 1990). Finally, cyclosporine has been reported to be effective in a dose of $6 \mathrm{mg} / \mathrm{kg}$ /day (in two equal doses) (Thivolet et al 1985). In general, once the patient who is receiving prednisone and an immunosuppressive agent attains complete remission, the prednisone is tapered and discontinued. The immunosuppressive agent is maintained and ultimately slowly tapered and discontinued.

Plasmapheresis may be used in severe cases and is usually used in association with immunosuppressive drugs
(Roujeau et al 1984; Goldberg et al 1985). A report of 41 patients documented the steroid-sparing effect of plasmapheresis (Roujeau et al 1984). Several years later a similar report failed to confirm the benefit of plasmapheresis in addition to glucocorticoid compared with glucocorticoid alone (Guillaume et al 1993). Plasmapheresis is costly, time consuming, and only temporarily beneficial. High dose IVIg is highly effective in selected cases (Engineer and Ahmed 2001b). The dose is similar to that used in patients with pemphigus. Since high dose IVIg is extremely expensive, it should be reserved for resistant cases. A recent review of four open, uncontrolled trials revealed that IVIg was effective in $70 \%$ of patients (Engineer and Ahmed 2001b). Dapsone (or sulfapyridine) has been reported to be of mild to moderate benefit in 110 cases (Person and Rogers 1977; Venning et al 1989; Phiamphonsongant 1993; Bouscarat et al 1996). Dapsone is started at $50 \mathrm{mg}$ daily and increased by $50 \mathrm{mg}$ increments every week until remission.

Tetracyclines (or erythromycin) with or without niacinamide (Berk and Lorincz 1986; Thomas et al 1993) has been used effectively in BP. In one study, the effectiveness of tetracycline and niacinamide was compared with that of prednisone in the treatment of generalized BP (Fivenson et al 1994). The two therapeutic regimens were equally effective. The dose of tetracycline was $500 \mathrm{mg}$ four times daily. It could be replaced with minocycline or doxycycline $100 \mathrm{mg}$ twice daily. The dose of niacinamide is $500 \mathrm{mg}$ three times daily. The use of a tetracycline with niacinamide may be indicated as sole therapy for very limited disease or as steroid-sparing in patients requiring adjuvant therapy. A recent report attempted to determine the evidence for treating BP from six randomized control trials that included 293 patients (Khumalo et al 2002). The authors could not derive any strong recommendations from the available evidence. An attempt at creating guidelines for treating BP have been reported (Khumalo et al 2002; Mutasim 2002; Wojnarowska et al 2002). Systemic glucocorticoids are the best established treatment. Consideration should be given to potent topical steroids for localized disease. For mild to moderate disease, a tetracycline and niacinamide may be considered. It is recommended that immunosuppressive agents be used only if glucocorticoid cannot be tapered to an acceptable level. The best established drug is azathioprine followed by methotrexate (Khumalo et al 2002). Figure 2 is a proposed algorithm for the treatment of BP. 


\section{Therapy of mucous membrane pemphigoid}

Therapy of mucous membrane pemphigoid (MMP) varies according to disease extent, severity and location (Anhalt and Morrison 1991). Patients with mild oral involvement are usually treated with topical therapy using topical anesthetic agents to control pain, as well as topical glucocorticoids. Oral hygiene is emphasized. The topical glucocorticoid may be applied under occlusion with a prosthetic device in order to increase its penetration. Alternatively, it may be injected into the lesion. Patients with moderate to severe oral involvement require systemic therapy (Jabs and Anhalt 1988). Some patients respond to dapsone (Rogers et al 1982; Rogers and Mehregan 1988; Fern et al 1992; Elder et al 1996). Oral lesions respond more rapidly than lesions in other mucous membranes. Treatment is started at $50 \mathrm{mg}$ daily and increased gradually as tolerated and as needed. Because of the dose-dependent hemolysis, the maximum dose is usually $200-300 \mathrm{mg}$ daily. A tetracycline with or without niacinamide may be effective in some patients (Poskitt and Wojnarowska 1995; Reiche et al 1998; Dragan et al 1999). In patients with severe oral lesions, as well as in patients with ocular, pharyngeal, or laryngeal involvement, a combination of systemic glucocorticoids with a steroid-sparing agent is indicated (Brody and Pirozzi 1977). Most patients who are treated with prednisone $1 \mathrm{mg} / \mathrm{kg} /$ day for six months and cyclophosphamide $1-2 \mathrm{mg} / \mathrm{kg} /$ day for $18-24$ months respond and have a prolonged or permanent remission. Azathioprine (Dave and Vickers 1974) and MMF are generally less effective but may be used in patients who cannot tolerate cyclophosphamide or prednisone. Multiple reports have documented the effectiveness of high dose IVIg in the treatment of MMP, including patients who were refractory to other therapies (Ahmed and Moy 1981; Foster and Ahmed 1999; Heilborn et al 1999; Letko et al 2000; Ahmed and Colon 2001; Mackay and Rosen 2001; Sami et al 2002a, 2002b).

\section{Therapy of epidermolysis bullosa acquisita}

Compared with BP, epidermolysis bullosa acquisita (EBA) is generally resistant to therapy (Taniuchi et al 1997). The disorder may present in one of two major forms. In type 1 EBA (mechanobullous), lesions result from minor trauma. In type 2 (inflammatory type), a neutrophil-rich cellular infiltrate mediates blister formation at the BMZ. Because of the neutrophil predominance, many patients with EBA respond to anti-neutrophil drugs such as dapsone (Taniuchi et al 1997; Huges and Callen 2001). Dapsone is started at $50 \mathrm{mg}$ daily and increased by $50 \mathrm{mg}$ every week until clinical remission or adverse effects (usually 100-250 mg daily). In patients who are allergic to dapsone, colchicine may be of benefit (Berbis and Privat 1989; Megahed and ScharffetterKochanek 1994; Cunningham et al 1996). The response to colchicine, however, is less predictable than that to dapsone. The dose of colchicine may be limited by the predictable gastrointestinal side effects (diarrhea). Patients who fail dapsone or colchicine or who are intolerant of the drugs may be treated with prednisone $1 \mathrm{mg} / \mathrm{kg} / \mathrm{day}$. The response is variable but generally good. Cyclosporine is a very potent steroid-sparing agent that may be used in patients who do not respond to glucocorticoids or who develop adverse effects. Cyclosporine is usually initiated in a dose of $4 \mathrm{mg} /$ $\mathrm{kg}$ /day in two equally divided doses (Engineer and Ahmed 2001a). The dose may be increased if there is only partial response. Several dosing regimens have been reported, ranging from $5 \mathrm{mg}$ to $9 \mathrm{mg} / \mathrm{kg} /$ day (Connolly and Sander 1987; Zachariae 1987; Crow et al 1988; Gupta et al 1990; Layton and Cunliffe 1990; Merle et al 1990; Klein et al 1991; Berger et al 1992; Clement et al 1993). Other immunosuppressive agents such as azathioprine or cyclophosphamide may be used. Patients who fail to respond may be treated with IVIg alone (Kofler et al 1996) or in combination with plasmapheresis (Taniuchi et al 1997). Other cases have been reported with variable response to IVIg either individually or in combination with other immunosuppressive agents (Meier et al 1993; Caldwell et al 1994; Mohr et al 1995; Kofler et al 1996; Jappe et al 2000). Patients with resistant disease may be treated with plasmapheresis (Furue et al 1986) or ECP (Gordon et al 1997; Heilborn et al 1999) in addition to immunosuppressive therapy (Gordon et al 1995; Miller et al 1995).

\section{Therapy of dermatitis herpetiformis}

Dermatitis herpetiformis (DH) results from an immune response to gluten. A completely gluten-free diet is extremely helpful in the management of $\mathrm{DH}$ and results in a marked decrease in the dose of pharmacologic therapy needed. Re-exposure to gluten results in a recurrence of the disease within a few months (Leonard et al 1983). Most patients find a gluten-free diet to be too restrictive. Pharmacologic therapy is aimed at the suppression of 


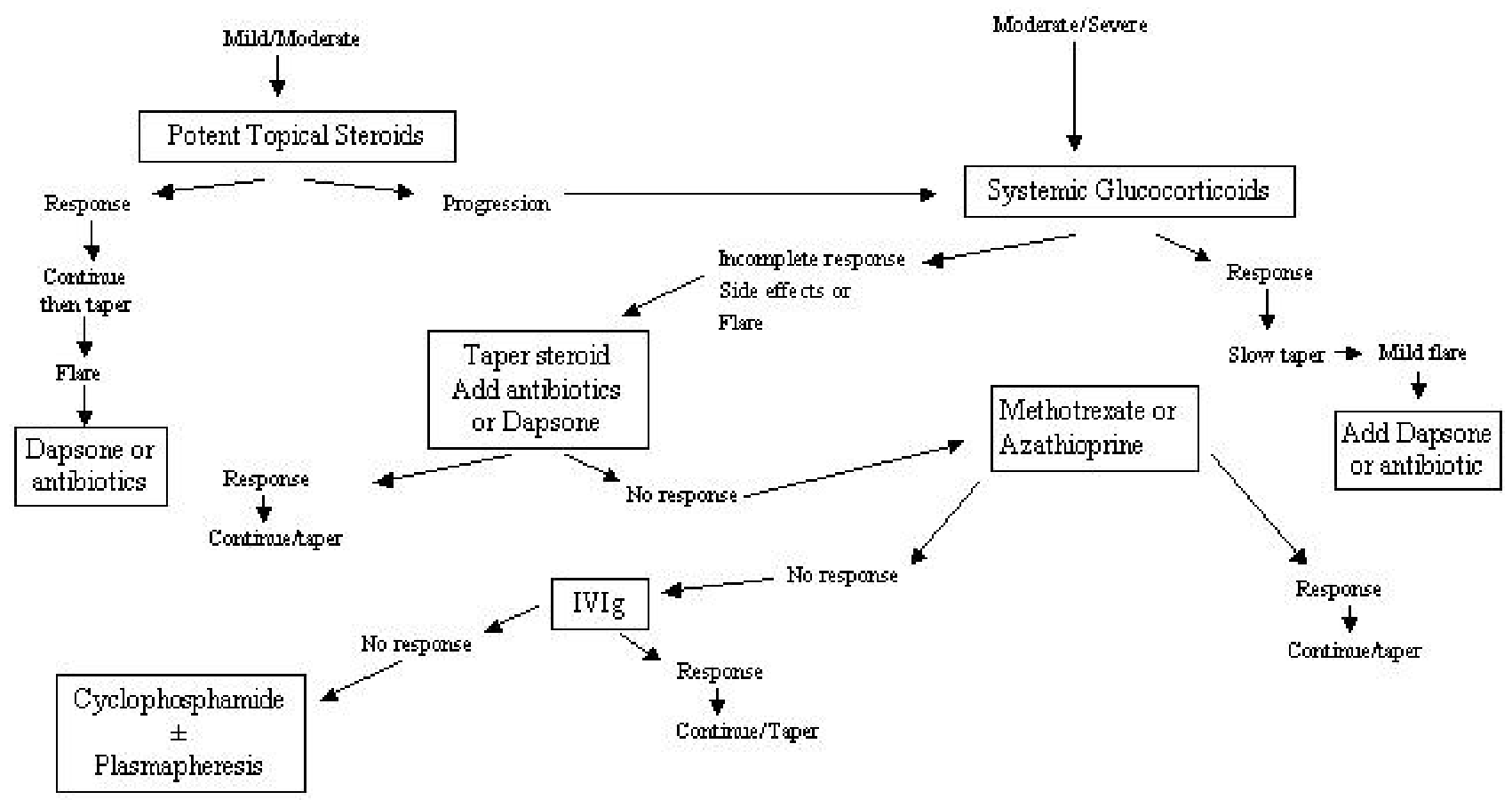

Figure 2 Algorithmic approach to the treatment of bullous pemphigoid. Abbreviations: $\mathrm{IVIg}$, intravenous immunoglobulin.

neutrophil chemotaxis in the skin. This is accomplished with dapsone. The initial dose is $50 \mathrm{mg}$ daily to be increased every week if needed until clearance or intolerance. The average daily dose is $100 \mathrm{mg}$. Patients who are allergic or intolerant of dapsone may be treated with sulfapyridine (Costello 1940). The initial dose is $500 \mathrm{mg}$ three times daily and may be increased slowly to $2 \mathrm{~g}$ three times daily. The response to sulfapyridine is less predictable than that to dapsone. Patients who are intolerant or allergic to dapsone and sulfapyridine may be treated with colchicine (Silvers et al 1980), cholestyramine (Shelley 1980) or tetracycline and niacinamide (Shah and Ormerod 2000). These agents, however, are much less effective than dapsone. Finally, topical steroids are of minimal benefit.

\section{Skin care}

Appropriate skin care is important in the healing of lesions and avoidance of complications. After blisters rupture, resulting erosions may become secondarily infected with bacteria, may progress to ulcers (especially over pressure areas such as the buttocks and the back), and may acquire crusting that interferes with reepithelialization and healing. Measures that help in the healing process include gentle cleansing of the erosions, liberal application of antibiotic ointments or petroleum jelly, and avoidance of trauma. The elderly are especially prone to complications and may require hospital admission for proper skin care.

\section{References}

Ahmed AR. 2001. Intravenous immunoglobulin therapy in the treatment of patients with pemphigus vulgaris unresponsive to conventional treatment. J Am Acad Dermatol, 45:679-90.

Ahmed AR, Colon JE. 2001. Comparison between intravenous immunoglobulin and conventional immunosuppressive therapy regimens in patients with severe oral pemphigoid. Arch Dermatol, 137:1181-9.

Ahmed AR, Moy R. 1981. Azathioprine. Int J Dermatol, 20:461-9.

Alijotas J, Pedragosa R, Bosch J, et al. 1990. Prolonged remission after cyclosporine therapy in pemphigus vulgaris: Report of two young siblings. J Am Acad Dermatol, 23:701-3.

Amagai M, Hashimoto T, Shimizu N, et al. 1994. Absorption of pathogenic autoantibodies by the extracellular domain of pemphigus vulgaris antigen (Dsg 3) produced by baculovirus. J Clin Invest, 94:59-67.

Amagai M, Karpati S, Prussick R, et al. 1992. Autoantibodies against the amino-terminal cadherin-like binding domain of pemphigus vulgaris antigen are pathogenic. J Clin Invest, 90:919-26.

Amagai M, Klaus-Kovtun V, Stanley JR. 1991. Autoantibodies against a novel epithelial cadherin in pemphigus vulgaris, a disease of cell adhesion. Cell, 67:869-77.

Amagai M, Tsunoda K, Suzuki H, et al. 2000. Use of autoantigen-knockout mice in developing an active autoimmune disease model for pemphigus. J Clin Invest, 105:625-31.

Anhalt GJ. 1997. Paraneoplastic pemphigus. Adv Dermatol, 12:77-96; discussion 7.

Anhalt GJ, Labib RS, Voorhees JJ, et al. 1982. Induction of pemphigus in neonatal mice by passive transfer of IgG from patients with the disease. N Engl J Med, 306:1189-96.

Anhalt GJ, Morrison LH. 1991. Bullous and cicatricial pemphigoid. Autoimmunity, 4:17-35. 
Barthelemey H, Frappaz A, Cambazard P, et al. 1988. Treatment of nine cases of pemphigus vulgaris with cyclosporine. J Am Acad Dermatol, 18:1262-6.

Basset N, Guillot B, Michel B, et al. 1987. Dapsone as initial treatment in superficial pemphigus. Report of nine cases. Arch Dermatol, 123:7835.

Berbis P, Privat Y. 1989. Value of colchicine in treating acquired epidermolysis bullosa. Ann Dermatol Venereol, 116:301-7.

Berger J, Gmur J, Bruckner-Tuderman L. 1992. EBA: a rare late complication of allogeneic bone marrow transplantation? Bone Marrow Transplant, 9:139-41.

Berk MA, Lorincz AL. 1986. The treatment of bullous pemphigoid with tetracycline and niacinamide. Arch Dermatol, 122:670-4.

Beutner EH, Jordon RE. 1964. Demonstration of skin antibodies in sera of pemphigus vulgaris patients by indirect immunofluorescent staining. Proc Soc Exp Biol Med, 117:505-10.

Borradori L, Lombardi T, Samson J, et al. 2001. Anti-CD20 monoclonal antibody (rituximab) for refractory erosive stomatitis secondary to $\mathrm{CD} 20(+)$ follicular lymphoma-associated paraneoplastic pemphigus. Arch Dermatol, 137:269-72.

Bouscarat F, Chosidow O, Picard-Dahan C, et al. 1996. Treatment of bullous pemphigoid with dapsone: retrospective study of 36 cases. $J$ Am Acad Dermatol, 34:683-4.

Bredlich R-O, Grundmann-Kollman M, Behrens S, et al. 1999. Mycophenolate mofetil monotherapy for pemphigus vulgaris. $\mathrm{Br} J$ Dermatol, 141:934.

Brody HJ, Pirozzi DJ. 1977. Benign mucous membrane pemphigoid. Response to therapy with cyclophosphamide. Arch Dermatol, 113:1598-9.

Burton JL, Greaves MW. 1974. Azathioprine for pemphigus and pemphigoid - a 4 year follow-up. Br J Dermatol, 91:103-9.

Bystryn JC. 1984. Adjuvant therapy of pemphigus. Arch Dermatol, 120:941-51.

Bystryn JC, Jiao D, Natow S. 2002. Treatment of pemphigus with intravenous immunoglobulin. $J$ Am Acad Dermatol, 47:358-63.

Bystryn J-C, Steinman NM. 1996. The adjuvant therapy of pemphigus. Arch Dermatol, 132:203-12.

Caldwell JB, Yancey KB, Engler RJM, et al. 1994. EBA: efficacy of high dose intravenous immunoglobulins. J Am Acad Dermatol, 31:827-8.

Church R. 1960. Pemphigoid treated with corticosteroids. Br J Dermatol, 72:431-41.

Clement M, Ratnesar P, Thirumoorthy T, et al. 1993. Epidermolysis bullosa acquisita: a case with upper airways obstruction requiring tracheostomy and responding to cyclosporine. Clin Exp Dermatol, 18:548-51.

Colonna L, Cianchini G, Frezzolini A, et al. 1998. Intravenous immunoglobulins for pemphigus vulgaris: adjuvant or first line therapy? Br J Dermatol, 138:1102-3.

Connolly SM, Sander HM. 1987. Treatment of EBA with cyclosporine. $J$ Am Acad Dermatol, 16:890.

Costello M. 1940. Dermatitis herpetiformis treated with sulfapyridine. Arch Dermatol Syphil, 41:134.

Crow LL, Finkle JP, Gammon WR, et al. 1988. Clearing of EBA with cyclosporine. J Am Acad Dermatol, 19:937-42.

Cunningham BB, Kirchmann TTT, Woodley D. 1996. Colchicine for epidermolysis bullosa acquisita. $J$ Am Acad Dermatol, 34:781-4.

Dave VK, Vickers CFH. 1974. Azathioprine in the treatment of mucocutaneous pemphigoid. Br J Dermatol, 90:183-6.

Dega H, LaPorte JL, Joly P, et al. 1998. Paraneoplastic pemphigus associated with Hodgkin's disease. Br J Dermatol, 138:196-7.

Diaz LA, Giudice GJ. 2000. End of the century overview of skin blisters. Arch Dermatol, 136:106-12.

Downham TF, Chapel TA. 1978. Bullous pemphigoid. Therapy in patients without diabetes mellitus. Arch Dermatol, 114:1639-42.

Dragan L, Eng AM, Lam S, et al. 1999. Tetracycline and niacinamide: treatment alternatives in ocular cicatricial pemphigoid. Cutis, 63:1813 .
Dumas V, Roujeau JC, Wolkenstein P, et al. 1999. The treatment of mild pemphigus vulgaris and pemphigus foliaceus with a topical corticosteroid. Br J Dermatol, 140:1127-9.

Dupuy A, Viguier M, Bedane C, et al. 2004. Treatment of refractory pemphigus vulgaris with rituximab (anti-CD20 monoclonal antibody). Arch Dermatol, 140:91-6.

Elder MJ, Leonard J, Dart JK. 1996. Sulphapyridine - a new agent for the treatment of ocular cicatricial pemphigoid. Br J Ophthalmol, 80:54952.

Engineer L, Ahmed AR. 2001a. Emerging treatment for epidermolysis bullosa acquisita. $J$ Am Acad Dermatol, 44:818-28.

Engineer L, Ahmed AR. 2001b. Role of intravenous immunoglobulin in the treatment of bullous pemphigoid: Analysis of current data. $J \mathrm{Am}$ Acad Dermatol, 44:83-8.

Engineer L, Bhol KC, Ahmed AR. 2000. Analysis of current data on the use of intravenous immunoglobulins in management of pemphigus vulgaris. J Am Acad Dermatol, 43:1049-57.

Enk AH, Knop J. 1997. Treatment of pemphigus vulgaris with mycophenolate mofetil. Lancet, 350:494.

Enk AH, Knop J. 1999. Mycophenolate is effective in the treatment of pemphigus vulgaris. Arch Dermatol, 135:54-6.

Espana A, Fernandez-Galar M, Lloret P, et al. 2004. Long-term complete remission of severe pemphigus vulgaris with monoclonal anti-CD20 antibody therapy and immunophenotype correlations. $J$ Am Acad Dermatol, 50:974-6.

Eyre RW, Stanley JR. 1988. Identification of pemphigus vulgaris antigen extracted from normal human epidermis and comparison with pemphigus foliaceus antigen. $J$ Clin Invest, 81:807-12.

Fellner MJ, Sapadin AN. 2001. Current therapy of pemphigus vulgaris. Mt Sinai J Med, 68:268-78.

Fern AI, Jay JL, Young H, et al. 1992. Dapsone therapy for the acute inflammatory phase of ocular pemphigoid. Br J Ophthalmol, 76:3325.

Fivenson DP, Breneman DL, Rosen GB, et al. 1994. Nicotinamide and tetracycline therapy of bullous pemphigoid. Arch Dermatol, 130:753-8.

Foster CS, Ahmed AR. 1999. Intravenous immunoglobulin therapy for ocular cicatricial pemphigoid. Ophthalmology, 106:2136-43.

Fullerton SH, Woodley DT, Smoller BR, et al. 1992. Paraneoplastic pemphigus with autoantibody deposition in bronchial epithelium after autologous bone marrow transplantation. JAMA, 267:1500-2.

Furue M, Iwata M, Yoon H, et al. 1986. Epidermolysis bullosa acquisita: clinical response to plasma exchange therapy and circulating antibasement membrane zone antibody titer. J Am Acad Dermatol, 14:8738 .

Goldberg NS, Robinson JK, Roenigk HH, Jr., et al. 1985. Plasmapheresis therapy for bullous pemphigoid. Arch Dermatol, 121:1484-5.

Gordon KB, Chan LS, Woodley DT. 1995. Treatment of refractory EBA with extracorporeal photochemotherapy. Br J Dermatol, 133:467-71.

Gordon KB, Chan LS, Woodley DT. 1997. Treatment of refractory epidermolysis bullosa acquisita with extracorporeal photochemotherapy. Br J Dermatol, 136:415-20.

Greaves MW, Burton JL, Marks J, et al. 1971. Azathiprine in treatment of bullous pemphigoid. $\mathrm{Br}$ Med $J, 1: 144-5$.

Grundmann-Kollman M, Kaskel P, Leiter U, et al. 1999. Treatment of pemphigus vulgaris and bullous pemphigoid with mycophenolate mofetil monotherapy. Arch Dermatol, 135:724-5.

Guillaume JC, Roujeau JC, Morel P, et al. 1988. Controlled study of plasma exchange in pemphigus. Arch Dermatol, 124:1659-63.

Guillaume JC, Vaillant L, Bernard P, et al. 1993. Controlled trial of azathioprine and plasma exchange in addition to prednisolone in the treatment of bullous pemphigoid. Arch Dermatol, 129:49-53.

Gupta AK, Ellis CN, Nickoloff BJ, et al. 1990. Oral cyclosporine in the treatment of inflammatory and noninflammatory dermatoses. A clinical and immunopathologic analysis. Arch Dermatol, 126:339-50.

Hayag MV, Cohen JA, Kerdel FA. 2000. Immunoablative high-dose cyclophosphamide without stem cell rescue in a patient with pemphigus vulgaris. $J$ Am Acad Dermatol, 43:1065-9. 
Heilborn JD, Stahle-Backdahl M, Albertioni F, et al. 1999. Low-dose oral pulse methotrexate as monotherapy in elderly patients with bullous pemphigoid. J Am Acad Dermatol, 40:741-8.

Heizmann M, Itin P, Wernli M, et al. 2001. Successful treatment of paraneoplastic pemphigus in follicular NHL with rituximab: report of a case and review of treatment for paraneoplastic pemphigus in NHL and CLL. Am J Hematol, 66:142-4.

Huges AP, Callen JP. 2001. Epidermolysis bullosa acquisita responsive to dapsone therapy. J Cutan Med Surg, 5:397-9.

Hymes SR, Jordon RE. 1992. Pemphigus foliaceus. Use of antimalarial agents as adjuvant therapy. Arch Dermatol, 128:1462-4.

Ioannides D, Chrysomallis F, Bystryn JC. 2000. Ineffectiveness of cyclosporine as an adjuvant to corticosteroids in the treatment of pemphigus. Arch Dermatol, 136:868-72.

Izaki S, Yoshizawa Y, Kitamura K, et al. 1996. Paraneoplastic pemphigus: potential therapeutic effect of plasmapheresis. Br J Dermatol, 134:9879.

Jablonska S, Chorzelski T. 1981. When and how to use sulfones in bullous diseases. Int J Dermatol, 20:103-5.

Jabs DA, Anhalt GJ. 1988. Cicatricial pemphigoid. In: Provost TT, Farmer ER (eds). Current therapy in dermatology 2. Philadelphia: BC Decker. p 56.

Jappe U, Sillikens D, Bonnekoh B, et al. 2000. EBA with ultraviolet radiation sensitivity. Br J Dermatol, 142:517-20.

Joly P, Roujeau J-C, Benichou J, et al. 2002. A comparison of oral and topical corticosteroids in patients with bullous pemphigoid. $N$ Engl $J$ Med, 346:321-7.

Karpati S, Amagai M, Prussick R, et al. 1993. Pemphigus vulgaris antigen, a desmoglein type of cadherin, is localized within keratinocyte desmosomes. J Cell Biol, 122:409-15.

Khumalo NP, Murrell DF, Wojnarowska F, et al. 2002. A systematic review of treatments for bullous pemphigoid. Arch Dermatol, 138:385-9.

Klein JS, Goldin HM, Keegan C, et al. 1991. Clear cell carcinoma of the lung in a patient treated with cyclosporine for EBA. J Am Acad Dermatol, 24:297.

Koch PJ, Mahoney MG, Ishikawa H, et al. 1997. Targeted disruption of the pemphigus vulgaris antigen (desmoglein 3 ) gene in mice causes loss of keratinocyte cell adhesion with a phenotype similar to pemphigus vulgaris. $J$ Cell Biol, 137:1091-102.

Kofler H, Wambacher-Gasser B, Topar G, et al. 1996. Intravenous immunoglobulin treatment in therapy-resistant epidermolysis bullosa acquisita. J Am Acad Dermatol, 34:331-5.

Krain LS, Landau JW, Newcomer VD. 1972. Cyclophosphamide in the treatment of pemphigus vulgaris and bullous pemphigoid. Arch Dermatol, 106:657-61.

Lapidoth M, David M, Ben-Amitai D, et al. 1994. The efficacy of combined treatment with prednisone and cyclosporine in patients with pemphigus: preliminary study. J Am Acad Dermatol, 30:752-7.

Layton AM, Cunliffe WJ. 1990. Clearing of EBA with cyclosporine. J Am Acad Dermatol, 22:535-6.

Leibowitz MR, Voss SP. 1993. Juvenile pemphigus foliaceous: response to dapsone. Arch Dermatol, 129:910.

Leonard J, Haffenden G, Tucker W, et al. 1983. Gluten challenge in dermatitis herpetiformis. $N$ Engl J Med, 308:816-9.

Letko E, Bhol K, Foster CS, et al. 2000. Influence of intravenous immunogloublin therapy on serum levels of anti-b4 antibodies in ocular cicatricial pemphigoid. Curr Eye Res, 21:646-54.

Liu Z, Diaz LA, Troy JL, et al. 1993. A passive transfer model of the organ-specific autoimmune disease, bullous pemphigoid, using antibodies generated against the hemidesmosomal antigen, BP 180. $J$ Clin Invest, 92:2480-8.

Liu Z, Giudice GJ, Zhou X, et al. 1997. A major role for neutrophils in experimental bullous pemphigoid. J Clin Invest, 100:1256-63.

Mackay IR, Rosen FS. 2001. Immunomodulation of autoimmune and inflammatory diseases with intravenous immune globulin. $N$ Engl $J$ Med, 345:747-55.
Megahed M, Scharffetter-Kochanek K. 1994. Epidermolysis bullosa acquisita - successful treatment with colchicine. Arch Dermatol Res, 286:35-40.

Meier F, Sonnichsen K, Schaumberg-Lever G, et al. 1993. Epidermolysis bullosa acquisita: efficacy of high-dose intravenous immunoglobulins. J Am Acad Dermatol, 29:334-7.

Merle C, Blanc D, Zultak M, et al. 1990. Intractable EBA: efficacy of ciclosporin A. Dermatologica, 181:44-7.

Miller JL, Stricklin GP, Fine JD, et al. 1995. Remission of severe EBA induced by extracorporeal photochemotherapy. $\mathrm{Br} J$ Dermatol, 133:467-71.

Milligan A, Hutchinson P. 1990. The use of chlorambucil in the treatment of bullous pemphigoid. J Am Acad Dermatol, 22:769-801.

Mimouni D, Anhalt GJ, Cummins DL, et al. 2003. Treatment of pemphigus vulgaris and pemphigus foliaceus with mycophenolate mofetil. Arch Dermatol, 139:739-42.

Mobini N, Padilla T, Ahmed AR. 1997. Long-term remission in selected patients with pemphigus vulgaris treated with cyclosporine. $\mathrm{J}$ Am Acad Dermatol, 36:264-6.

Mohr C, Sunderkotter C, Hildebrand A, et al. 1995. Successful treatment of EBA using intravenous immunoglobulins. Br J Dermatol, 132:8246.

Mutasim DF. 2002. Treatment considerations while awaiting the ideal bullous pemphigoid trial. Arch Dermatol, 138:404.

Mutasim DF. 2004. Management of autoimmune bullous diseases: pharmacology and therapeutics. J Am Acad Dermatol, 51:859-77; quiz 78-80.

Mutasim DF, Adams BB. 2001. Immunofluorescence in dermatology. $J$ Am Acad Dermatol, 45:803-22.

Mutasim DF, Sheth P. 2002. An eruption secondary to intravenous immunoglobulin therapy. Cutis, 69:35-8.

Nousari CH, Brodsky R, Anhalt GJ. 2003. Evaluating the role of immunoablative high-dose cyclophosphamide therapy in pemphigus vulgaris. J Am Acad Dermatol, 49:148-50.

Nousari HC, Brodsky RA, Jones RJ, et al. 1999. Immunoablative highdose cyclophosphamide without stem cell rescue in paraneoplastic pemphigus: report of a case and review of this new therapy for severe autoimmune disease. $J$ Am Acad Dermatol, 40:750-4.

Nousari HC, Griffin WA, Anhalt GJ. 1998. Successful therapy for bullous pemphigoid with mycophenolate mofetil. J Am Acad Dermatol, 39:497-8.

Nousari HC, Sragovich A, Kimyai-Asadi A, et al. 1999. Mycophenolate mofetil in autoimmune and inflammatory skin disorders. $J$ Am Acad Dermatol, 40:265-8.

Pandya AG, Dyke C. 1998. Treatment of pemphigus with gold. Arch Dermatol, 134:1104-7.

Perniciaro C, Kuechle MK, Colon-Otero G, et al. 1994. Paraneoplastic pemphigus: a case of prolonged survival. Mayo Clin Proc, 69:851-5.

Person JR, Rogers RS, III. 1977. Bullous pemphigoid responding to sulfapyridine and the sulfones. Arch Dermatol, 113:610-15.

Phiamphonsongant T. 1993. Dapsone for the treatment of bullous pemphigoid. Asian Pacific J Allergy Immunol, 1:19-21.

Poskitt L, Wojnarowska F. 1995. Minimizing cicatricial pemphigoid orodynia with minocycline. Br J Dermatol, 132:784-9.

Poulin Y, Perry HO, Muller SA. 1984. Pemphigus vulgaris: Results of treatment with gold as a steroid-sparing agent in a series of 13 patients. J Am Acad Dermatol, 11:851-7.

Rappersberger K, Roos N, Stanley JR. 1992. Immunomorphological and biochemical identification of the pemphigus foliaceus autoantigen within desmosomes. $J$ Invest Dermatol, 99:323-30.

Reiche L, Wojnarowska F, Mallon E. 1998. Combination therapy with nicotinamide and tetracyclines for cicatricial pemphigoid: further support for its efficacy. Clin Exp Dermatol, 23:254-7.

Rogers RS, 3rd., Seehafer JR, Perry HO. 1982. Treatment of cicatricial (benign mucous membrane) pemphigoid with dapsone. $J$ Am Acad Dermatol, 6:215-23. 
Rogers RS, III, Mehregan DA. 1988. Dapsone therapy of cicatricial pemphigoid. Semin Dermatol, 7:201-5.

Rook AH, Jegasothy BV, Heald P, et al. 1990. Extracorporeal photochemotherapy for drug-resistant pemphigus vulgaris. Ann Intern Med, 112:303-5.

Roscoe JT, Diaz L, Sampaio SA, et al. 1985. Brazilian pemphigus foliaceus autoantibodies are pathogenic to BALB/c mice by passive transfer. $J$ Invest Dermatol, 85:538-41.

Roujeau JC, Guillaume JC, Morel P, et al. 1984. Plasma exchange in bullous pemphigoid. Lancet, 2:486-9.

Salomon D, Saurat JH. 1986. Oral gold therapy (auranofin) in pemphigus vulgaris. Dermatologica, 172:310-14.

Salopek TG, Logsetty S, Tredget EE. 2002. Anti-CD20 chimeric monoclonal antibody (rituximab) for the treatment of recalcitrant, lifethreatening pemphigus vulgaris with implications in the pathogenesis of the disorder. J Am Acad Dermatol, 47:785-8.

Sami N, Bhol KC, Ahmed AR. 2002a. Intravenous immunoglobulin therapy in patients with multiple mucosal involvement in mucous membrane pemphigoid. Clin Immunol Immunopathol, 102:59-67.

Sami N, Bhol KC, Ahmed AR. 2002b. Treatment of oral pemphigoid with intravenous immunoglobulin as monotherapy. Long-term follow-up: influence of treatment on antibody titres to human a6 integrin. Clin Exp Immunol, 129:533-40.

Schoen H, Foedinger D, Derfler K, et al. 1998. Immunoapheresis in paraneoplastic pemphigus. Arch Dermatol, 134:706-10.

Shah SA, Ormerod AD. 2000. Dermatitis herpetiformis effectively treated with heparin, tetracycline and nicotinamide. Clin Exp Dermatol, 25:204-5.

Shelley WB. 1980. Treatment of dermatitis herpetiformis with cholestyramine. Br J Dermatol, 103:663-6.

Siegel J, Eaglstein WH. 1984. High-dose methylprednisolone in the treatmen tof bullous pemphigoid. Arch Dermatol, 120:1157-65.

Silvers DN, Juhlin EA, Berczeller PH, et al. 1980. Treatment of dermatitis herpetiformis with colchicine. Arch Dermatol, 116:1373-84.
Smith TJ, Bystryn JC. 1999. Methotrexate as an adjuvant treatment for pemphigus vulgaris. Arch Dermatol, 135:1275-6.

Stanley JR. 1989. Pemphigus and pemphigoid as paradigms of organspecific, autoantibody-mediated diseases. J Clin Invest, 83:1443-8.

Stanley JR. 1993. Cell adhesion molecules as targets of autoantibodies in pemphigus and pemphigoid, bullous diseases due to defective epidermal cell adhesion. Adv Immunol, 53:291-325.

Su WP, Oursler JR, Muller SA. 1994. Paraneoplastic pemphigus: a case with high titer of circulating anti-basement membrane zone autoantibodies. J Am Acad Dermatol, 30:841-4.

Taniuchi K, Inaoki M, Nishimura Y, et al. 1997. Nonscarring inflammatory epidermolysis bullosa acquisita with esophageal involvement and linear IgG deposits. J Am Acad Dermatol, 36:320-2.

Tan-Lim R, Bystryn JC. 1990. Effect of plasmapheresis therapy on circulating levels of pemphigus antibodies. J Am Acad Dermatol, 22:35-40.

Thivolet J, Barthelemy H, Rigot-Muller G, et al. 1985. Effects of cyclosporin on bullous pemphigoid and pemphigus. Lancet, 1:334-5.

Thomas I, Khorenian S, Arbesteld DM. 1993. Treatment of generalized bullous pemphigoid with oral tetracycline. J Am Acad Dermatol, 28:74-7.

Turner MS, Sutton D, Sauder DN. 2000. The use of plasmapheresis and immunosuppression in the treatment of pemphigus vulgaris. $J$ Am Acad Dermatol, 43:1058-64.

Venning VA, Millard PR, Wojnarowska F. 1989. Dapsone as first line therapy for bullous pemphigoid. Br J Dermatol, 120:83-92.

Werth VP. 1996. Treatment of pemphigus vulgaris with brief, high-dose intravenous glucocorticoids. Arch Dermatol, 132:1435-9.

Wojnarowska F, Kirtschig G, Highet AS, et al. 2002. Guidelines for the management of bullous pemphigoid. Br J Dermatol, 147:214-21.

Wollina U, Lange D, Looks A. 1999. Short-time extracorporeal photochemotherapy in the treatment of drug-resistant autoimmune bullous disease. Dermatology, 198:140-4.

Zachariae H. 1987. Cyclosporine A in EBA. J Am Acad Dermatol, 17:10589. 